\title{
Geology and development
}

The 31st International Geological Congress, scheduled to occur for the first time in South America in the year 2000, will address the main theme "Geology and Sustainable Development: Challenge for the Third Millennium". The subject was chosen to stimulate geologists to think about the importance of Geology for society, and the role of the Earth Sciences in the ideal sustainable world to be reached in the next decades. These reflections are related to the main questions of environment and development, of crucial importance for the future of mankind, that were fully considered by the United Nations at the largest ever meeting of heads of state, held in Rio de Janeiro in 1992, the UN Conference on Environment and Development, the "Rio-92" or "UNCED-92".

At the UNCED-92, such issues were made openly accessible to the public all over the world, and governmental executives unanimously agreed with the principles of the Agenda 21 , a comprehensive document describing how to bring about in a few decades a situation of social justice for humanity, in which socio-economic development could be reached, equitable and sustainable, in harmony with the life support systems throughout our planet. A great deal of scientific and technological knowledge is already available in terms of environmentally friendly technologies, recycling of industrial wastes, regenerative agriculture, and so on. However, some issues are still far from resolved, such as the supply of renewable energy, and the growth of the global population.

In such global processes, scientists and professionals of the Earth Sciences already have an important role to play, as put forth in several recent articles and editorials in Episodes, for instance, those of Minister Song Ruixiang, President Robin Brett, or Past President Bill Fife. Geology is and will be important in the search, provision and management of mineral and energetic resources, in the protection, conservation and management of soils and water resources, in the continuous monitoring of the dynamic processes of the Earth system, and in the prevention and mitigation of natural disasters.

For the materialization of the perhaps utopical principles of the Agenda 21, strong determination of all international actors is needed. This includes political disposition on the part of governments, and especially social solidarity among all people of different origins and different races.

National societies are presently going through great transformations, with a continuous trend towards a global society. The environmental question is becoming more and more important, when finally we realised that we live on a small planet, which is reaching saturation in many different ways. Moreover, the current process of economic globaliza- tion is no longer commanded by the nation-states, but mainly by transnational business corporations, which are in fact becoming new centers of political power. They act according to their specific interests, driven by the rules of the free markets, where efficiency, profits, low cost-high benefits activities, and so on, are the paradigms. In this realm, environmental preservation and socio-economic development of the Third World countries become of very little relevance.

In the industrialized countries, environmental degradation is one of the main concerns, and they are presently making great efforts in the cleaning of their own territories. In the developing countries, however, although the environmental issues are becoming increasingly important, the difficulties and the urgent problems, such as famine, diseases, or mere survival in the face of natural disasters, are so demanding, that environmental concerns become secondary, increasing the already large stresses on existing ecosystems. And there's more: in a few decades, about $85 \%$ of the world population will live in Third World countries!

In my view, this is the main dilemma that faces a global society. We need widespread social solidarity among our generation, while also taking into account the needs of future generations in order to draw closer to the vision of a sustainable society. But where can we find this? How can we expect that the free markets, while trying to promote economic development, will take care at the same time of their negative social impacts? How can free markets improve the present situation of social differences and social injustice?

The only answer that I can see is environmental education, providing awareness of earth processes and instruction on the wise management of our planet and its resources. In my view, we geologists have a great responsibility in bringing about sustainable development. We have the expertise in dealing with the surface of our planet, and we are familiar with observation and monitoring of the Earth processes, as well as map construction and interpretation. Such expertise must be shared and integrated with that of our colleagues engineers, economists, ecologists and the like - and we must become active in instructing politicians, educators, and the general public in order to achieve the wisest planning of developmental activities and avoid crucial mistakes.

\author{
Umberto G. Cordani \\ Professor, University of São Paulo, Brazil \\ Ex-President, IUGS and \\ President, 31st IGC's Organizing Committee
}

\section{EDUCATIONAL POSTERS}

The IUGS, with support from ICSU and UNESCO, is preparing educational posters for schools. They will focus on key issues in sustainable development. The first is on water, a global problem, which was circulated in the last issue of Episodes.

The posters with the question list are designed for an intelligent 10-12 year old student. Please give them to your local school teachers. You are free to copy, translate as you wish. And we would appreciate your comments and criticisms. We hope the next will be on energy for all.

W.S. Fyfe 